\title{
Non-atherosclerotic coronary artery disease and sudden death in the young
}

\author{
Domenico Corrado, Gaetano Thiene, Patrizia Cocco, Carla Frescura
}

\begin{abstract}
Objective-To assess prevalence and type of non-atherosclerotic coronary artery disease in young people $(\leqslant 35$ years) who died suddenly.

Design-A necropsy study of 150 consecutive cases of sudden death (that is, within $6 \mathrm{~h}$ of the onset of symptoms).

Results-Death was attributed to coronary artery disease in $\mathbf{4 8}$ cases: in $\mathbf{1 6}$ $(33 \%)$ of them the disease was nonatherosclerotic. Twelve subjects (eight males and four females, age range 2-35 years, mean 24.2) had congenital anomalies: a deep intramyocardial course in six, origin from the wrong sinus in three, and ostial obstructions in three. Sudden death was the first manifestation of disease in six cases. The other six had a history of palpitation or syncope or both. An electrocardiogram was available in five cases and showed ventricular arrhythmias in four; none had angina pectoris. Stress testing was available in two cases: neither showed any effortdependent ST-T abnormalities. In six cases sudden death was related to physical exercise. Acquired nonatherosclerotic coronary artery disease was found in four cases: spontaneous coronary dissection in three previously symptom free patients and Kawasaki coronary arteritis in one child who had had acute myocardial infarction.

Conclusion-One third of the cases of fatal coronary artery disease were nonatherosclerotic with coronary artery anomalies being the most frequent form. Coronary artery anomalies should be suspected in young patients who have symptoms of ventricular arrhythmias without any overt signs and symptoms of ischaemia.
\end{abstract}

(Br Heart J 1992;68:601-7).

Clinical and pathologic studies have shown that atherosclerotic coronary artery disease, often complicated by acute thrombosis, is the most common cause of sudden death in adults. ${ }^{1-3}$ The few studies of sudden death in young people showed that in this subgroup ischaemic cardiac arrest was often triggered by nonatherosclerotic coronary artery disease. ${ }^{4-10}$ The incidence, clinical significance, mechanism of ischaemia, and possibility of early diagnosis of non-atherosclerotic disease have not been studied, however.

We report here the clinical and pathological findings in a group of young people who died suddenly of non-atherosclerotic coronary artery disease since 1979 in the Veneto region (northeast) of Italy.

\section{Patients and methods}

The Veneto region covers an area of 18368 $\mathrm{km} .^{2}$ In the 1985 census it had a population of 4370 533. The residents are white and the population is ethnically homogeneous. Italian law does not require postmortem examination of all persons who die suddenly so fatal cases were reported to pathologists or medical examiners only at the specific request of the General Attorney. All sudden deaths reported during this period were included in this study, but we do not know how many cases were not referred for postmortem examination. After necropsy the hearts were forwarded to the Institute of Pathological Anatomy of the University of Padua for detailed morphological study.

From 1 January 1979 to 30 September 1991 we collected 150 consecutive cases of juvenile sudden death, which was defined as an unexpected natural fatal outcome within $6 \mathrm{~h}$ of the initial symptoms in people aged 35 or less; cases of infant sudden death syndrome were excluded. The methods of investigation have been reported in detail elsewhere. ${ }^{8911}$

There were 126 sudden fatal cardiovascular events and death was attributed to coronary artery disease in 48 cases: 32 had obstructive atherosclerotic coronary artery disease and 16 $(33 \%)$ had non-atherosclerotic coronary artery disease.

Sudden death was deemed to be coronary in origin in the absence of other cardiac pathology and in the presence of ischaemic damage in the myocardial territory supplied by the affected coronary artery.

\section{Results}

The table shows the main clinical and pathological findings.

Twelve individuals ( 8 male and 4 female, aged 2-35 years (mean 21.6) had congenital coronary anomalies. In six the fatal event occurred at rest and in six it was related to physical exercise (during effort in five and after effort in one). In six sudden death was the first manifestation of the disease. The other six had a history of palpitation or syncope or both; a resting electrocardiogram was available in five and had showed isolated ventricular extrasystoles in four (fig 1 A and B). Ambulatory Holter monitoring was available in two. It showed complex ventricular arrhythmias consisting of ventricular couplets in patient 5 and non-sus- 
Sudden death in the young caused by non-atherosclerotic coronary artery disease: main clinical and pathologic findings in 16 subjects

\begin{tabular}{|c|c|c|c|c|c|}
\hline $\begin{array}{l}\text { Case } \\
\text { No }\end{array}$ & $\begin{array}{l}\text { Age, } \\
\text { sex }\end{array}$ & History & Previous ECG findings & Circumstances of death & Main pathological findings \\
\hline \multicolumn{6}{|c|}{ Congenital coronary anomalies } \\
\hline $\begin{array}{l}1 \\
2\end{array}$ & $\begin{array}{l}22, M \\
29, M\end{array}$ & $\begin{array}{l}\text { Athlete, palpitation } \\
\text { Athlete, palpitation }\end{array}$ & $\begin{array}{l}\text { Ventricular extrasystoles } \\
\text { Ventricular extrasystoles, normal } \\
\text { stress testing }\end{array}$ & $\begin{array}{l}\text { During effort } \\
\text { During effort }\end{array}$ & \multirow{3}{*}{$\begin{array}{l}\text { RCA from left coronary sinus } \\
\text { RCA from left coronary sinus. } \\
\text { Healed myocardial infarction } \\
\text { LCA from right coronary sinus } \\
\text { Intramyocardial course of LAD }\end{array}$} \\
\hline 3 & $11, \mathrm{~F}$ & Symptom free & Not performed & During effort & \\
\hline 4 & $19, \mathrm{~F}$ & $\begin{array}{l}\text { Family history of sudden death; } \\
\text { symptom free }\end{array}$ & Normal standard ECG & During sleep & \\
\hline 5 & $30, \mathrm{~F}$ & Palpitation & $\begin{array}{l}\text { Multiform extrasystoles, ventricular } \\
\text { couplets }\end{array}$ & At rest & Intramyocardial course of LAD \\
\hline 6 & $27, M$ & Symptom free & Not performed & At rest & \multirow{3}{*}{$\begin{array}{l}\text { Intramyocardial course of LAD } \\
\text { Intramyocardial course of LAD } \\
\text { Intramyocardial course of left } \\
\text { intermediate coronary artery }\end{array}$} \\
\hline 7 & $35, \mathrm{M}$ & Symptom free & Not performed & During effort & \\
\hline 8 & $14, M$ & Athlete, effort-induced syncope & $\begin{array}{l}\text { Ventricular extrasystoles and } \\
\text { unsustained ventricular } \\
\text { tachycardia, normal stress testing }\end{array}$ & During effort & \\
\hline 9 & $29, M$ & Symptom free & Not performed & At rest & \multirow{2}{*}{$\begin{array}{l}\text { Intramyocardial course of LAD } \\
\text { Slit-like lumen of left coronary } \\
\text { ostium }\end{array}$} \\
\hline 10 & $2, \mathrm{M}$ & Recurrent syncope & Not performed & After meal & \\
\hline 11 & $7, \mathrm{~F}$ & Recurrent syncope & Normal standard ECG & After effort & $\begin{array}{l}\text { Valve-like ridge of right coronary } \\
\text { ostium }\end{array}$ \\
\hline 12 & $35, M$ & Symptom free & Not performed & After meal & $\begin{array}{l}\text { Valve-like ridge of right coronary } \\
\text { ostium }\end{array}$ \\
\hline \multicolumn{6}{|c|}{ Acquired non-atherosclerotic coronary artery disease } \\
\hline 13 & $34, F$ & Asymptomatic & Not performed & During sleep & Spontaneous LAD dissection \\
\hline 14 & $28, F$ & Pregnancy, Marfan; symptom free & Not available & At rest & Spontaneous LM dissection \\
\hline 15 & $23, \mathrm{M}$ & Symptom free & Not performed & At rest & Spontaneous LAD dissection \\
\hline 16 & $6, M$ & Previous myocardial infarction & Not available & At rest & Kawasaki coronary arteritis \\
\hline
\end{tabular}

RCA, right coronary artery; LAD, left anterior descending coronary artery; LM, left main coronary artery.

tained ventricular tachycardia in patient 8 , in whom neither conduction disturbances nor ventricular tachycardia had been induced during electrophysiological study with programmed ventricular stimulation.

No patient had angina pectoris, and electrocardiographic stress testing in two patients (cases 2 and 8 ) had not shown any effortdependent ST-T abnormalities.

Postmortem examination in six cases showed that a subepicardial coronary artery (the proximal tract of the left anterior descending branch in five (fig 2) and the intermediate branch of the left coronary artery in one (fig 3 )) followed a deep intramyocardial course. The length of the intramyocardial course ranged from 10 to 25 $\mathrm{mm}$ and the depth from 4 to $8 \mathrm{~mm}$. Histological examination showed that the intramyocardial coronary segments were separated from the subepicardial fat by a myocardial bridge and were also encircled by a muscular "sheath" that compressed and deformed the coronary lumen; moreover, we found myocardial disarray around the intramural segment in four cases (fig 4). In every case the myocardial tributary of the intramural coronary artery showed histological features of ischaemic injury, consisting of an acute myocardial infarction of the left ventricular lateral wall (case 8) (fig 3B), a postinfarction scar in the interventricular septum (case 5), and signs of "hyperacute" myocardial damage such as contraction band necrosis (fig 2B) and wavy fibres in the anteroseptal wall of the left ventricle in the four other cases.

A coronary artery originated from the wrong aortic coronary sinus in three cases. In two (cases 1 and 2) both the right and left coronary arteries arose from the left coronary sinus (fig $1 \mathrm{C})$ and the proximal tract of the right coronary artery ran between the aorta and the pulmonary infundibulum, following an intramural course in the aortic tunica media and with a slit-like lumen. We found scattered foci of contraction band necrosis in the posteroseptal wall of the left ventricle in both cases and an extensive healed posterior myocardial infarction in one (case 2). In case 3 the left coronary artery had an anomalous origin from the right coronary sinus and ran between the aorta and pulmonary artery and partially within the wall of the aorta (fig 5); a large anterior subacute myocardial infarction was also seen.

Isolated malformations that obstructed the ostial lumen were found in three cases. In two (cases 11 and 12) the right ostium was obstructed by a valve-like ridge produced by a fold in the elastic tunica media of the aorta (fig 6). In the third (case 10) the left coronary ostium had a slit-like lumen caused by stenosis (fig 7).

There was evidence of acquired nonatherosclerotic coronary artery disease in four cases (two male and two female, aged 6-34 years (mean 22.7 years)). In three previously symptom free subjects sudden death was caused by spontaneous coronary dissection: in one patient (case 14) with Marfan's syndrome who was pregnant, the left main stem was affected. In the other two (cases 13 and 15), who had no risk factors, the dissection affected the left descending coronary artery. Cystic medial necrosis was seen only in the case with Marfan's syndrome.

Case 16 died suddenly three years after a myocardial infarction. The postmortem examination showed Kawasaki coronary arteritis causing aneurysms and thrombosis of all the proximal subepicardial coronary arterial trunks, leading to severe ischaemic cardiomyopathy.

\section{Discussion}

Postmortem examinations after sudden cardiac death in adults, ${ }^{12}{ }^{13}$ and coronary arteriography studies in survivors of cardiac arrest generally showed extensive coronary atherosclerosis. ${ }^{12}$ Unlike these older populations, $33 \%$ of cases of fatal coronary artery disease in our juvenile series were caused by non-atherosclerotic dis- 
A
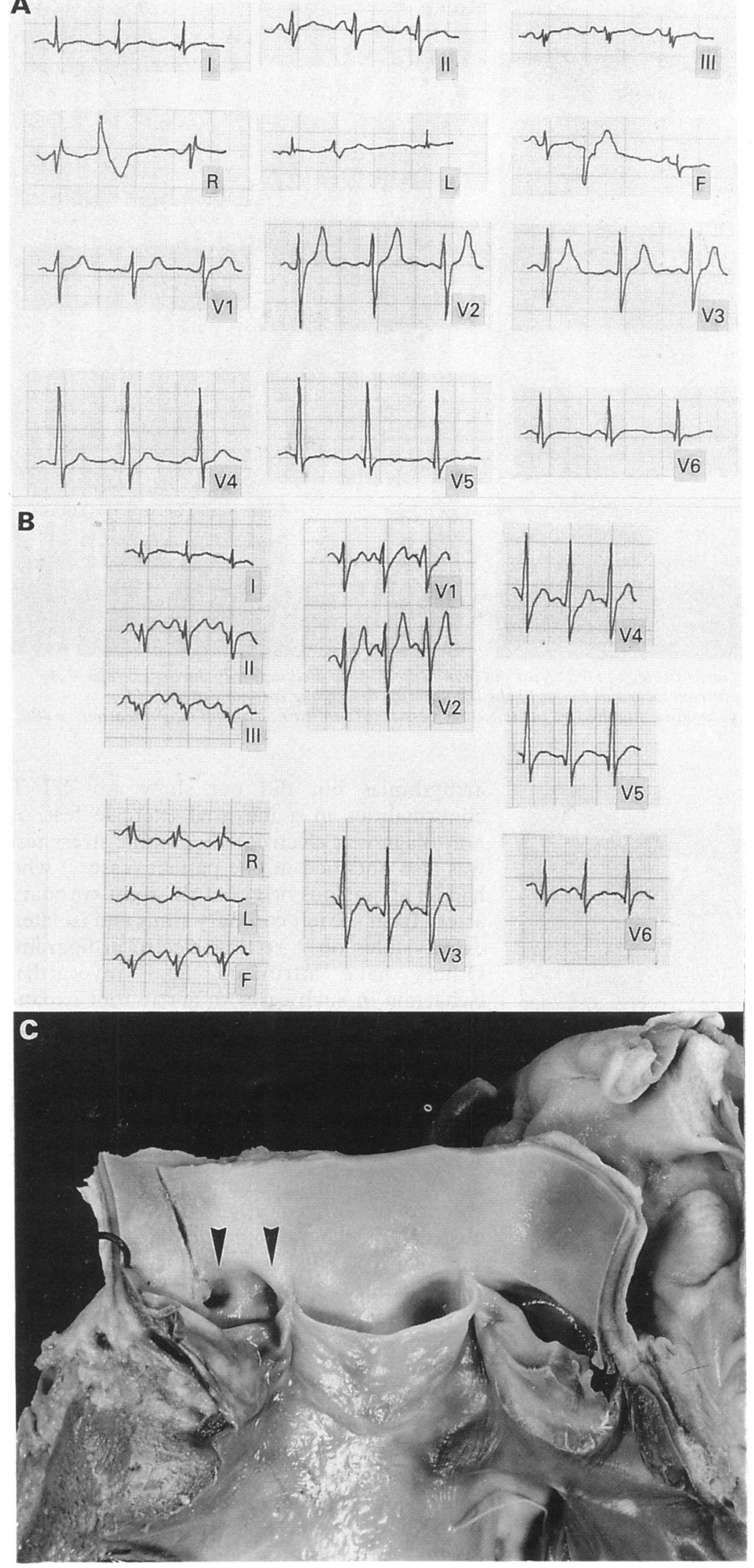

Figure 1 Electrocardiograms (ECG) and cardiac morphology in a 29 year old male athlete (case 2) who died suddenly during effort. (A) Resting ECG showing isolated athlete (case 2) who died suddenly during effort. (A) Resting ECG showing isolated
ventricular extrasystoles. (B) The ECG during effort did not show any ischaemic $S T-T$ ventricular extrasystoles. (B) The ECG during effort did not show any ischaemic ST-
changes or arrhythmias. (C) Gross view of the aortic root showing that both coronary ostia originated from the left coronary sinus (arrows).

ease-chiefly congenital anomalies in the origin and course of coronar: arteries, which were found in about $10 \%$ of all cases of cardiovascular sudden death. This finding accords with previous studies that identified congenital coronary artery disease as the cause of 5-35\% of the cases of sudden cardiac death in young people..$^{47}$ However, in contrast to previously published series in which the most common coronary anomaly was an origin from the "wrong" coronary sinus, we found a wider range of abnormalities including coronary ostial malformations and the coronary trunks following an intramyocardial course. This latter condition has long been regarded as a normal anatomical variant ${ }^{14}$; ; however, recent clinical and pathological studies showed that myocardial bridging of the coronary arteries can lead to myocardial ischaemia manifested as angina, ${ }^{16-18}$ myocardial infarction, ${ }^{18-20}$ and sudden death. ${ }^{21}$ Faruqhi et al reported a significant clinical improvement in ischaemic symptoms after surgical debridging of the coronary artery. ${ }^{18}$

The role of intramyocardial coronary arteries in precipitating fatal myocardial ischaemia during strenuous exercise was confirmed by Morales et al in a pathological study. They found ischaemic damage at various stages of healing in the myocardial territory supplied by the intramural coronary artery. ${ }^{21}$ Nonetheless, the pathophysiology of myocardial ischaemia caused by gross epicardial coronary trunks taking an intramyocardial course is still unknown. Effort-induced ischaemia has been attributed to tachycardia which increases the myocardial oxygen requirement and reduces the coronary flow during diastole. ${ }^{18}$ Ischaemia at rest, however, could be caused by vasospasm in the intramural coronary segment ${ }^{22-25}$ and the transient formation of platelet aggregate $\mathrm{s}^{20}$ and/ or thrombosis ${ }^{19}$ provoked by mechanical trauma of the vessel wall. The importance of myocardial bridging in patients who died suddenly is uncertain because this feature is not uncommon in healthy individuals. Ferreira $e t$ al examined a series of hearts at necropsy. ${ }^{26}$ They found that myocardial bridging was common but that only a deep and long intramyocardial course caused myocardial ischaemia. We too found that when a coronary artery followed a particularly deep and long intramyocardial course it could cause ischaemic cardiac arrest. We often found signs of hyperacute, recent or healed ischaemic injury in the myocardial territory supplied by a tributary of the intramural coronary artery. Case 14 is paradigmatic in that, to the best of our knowledge, it is the first reported necropsy case of effortinduced regional acute myocardial infarction with a corresponding intramural coronary arterial trunk.

Where a coronary artery followed a long and deep intramyocardial course we found the distinctive histological feature of ventricular myocardium organised to form a "sheath" encircling the intramural coronary segment with myocardial disarray and fibrosis. Could this myocardial ring have caused paroxysmal obstruction of the intramural coronary segment by inducing "extrinsic" prolonged constriction? At angiography this mechanism can be indistinguishable from an "intrinsic" coronary vasospasm. ${ }^{22-25}$ Alternatively, the myocardial disarray and fibrosis surrounding the 

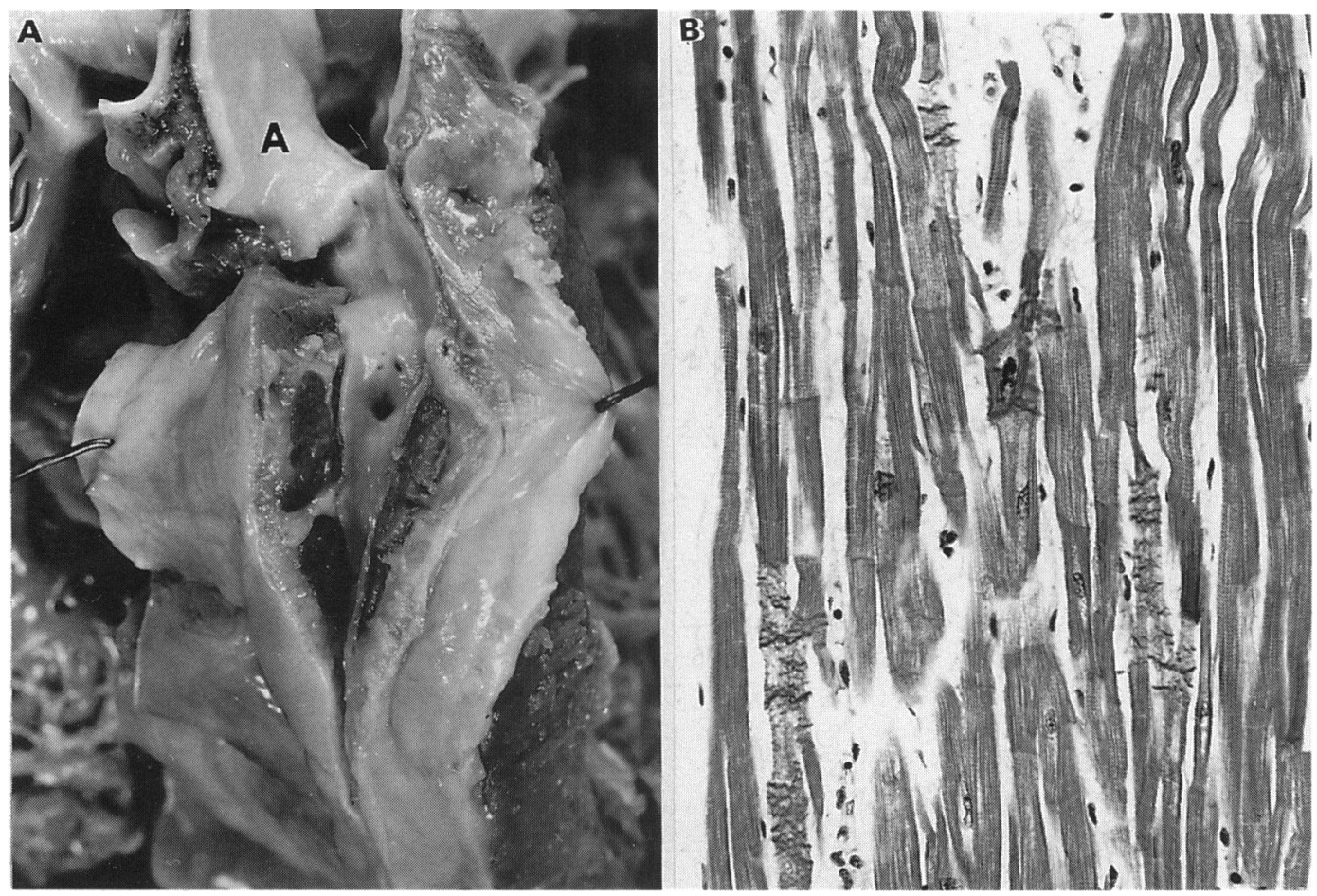

Figure 2 Cardiac morphology and histology in a 35 year old man (case 7 ) who died suddenly during exercise. ( $A$ ) Gross view of the deep and long intramyocardial course of the left anterior descending coronary artery. (B)

Contraction band necrosis in myocardium supplied by the tributary vessel. (Azan stain; original magnification, $\times 480$ $A$, aorta).

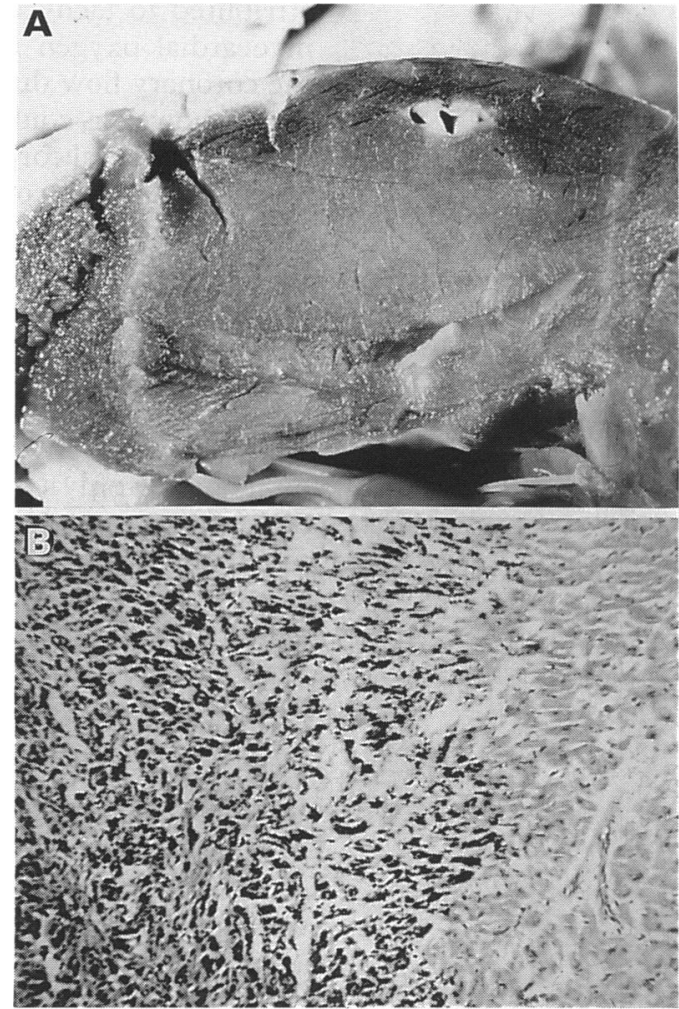

Figure 3 Cardiac morphology and histology in a 14 year old boy who died suddenly during a soccer game (case 8). (A) Gross view of the lateral left ventricular free wall showing a deep intramyocardial course of the intermediate branch of the left coronary artery. (B) Massive necrosis in the tributary myocardium. (Acid phosphotungstic stain; original magnification, $\times 75$ ).

intramural vessel might have acted as a "restrictive" perivascular tissue to limit the diastolic flow in the coronary segment.

Case 14 had complained of syncope and had electrocardiographic evidence of ventricular arrhythmias but did not show any ST-T abnormalities in a maximal exercise test. A non-diagnostic electrocardiographic stress test was also obtained in one patient (case 2) who had an anomalous origin of the right coronary artery from the left coronary sinus and isolated extrasystoles on a resting electrocardiogram. Others have attributed fatal myocardial ischaemia in such cases to aortic root expansion, which increases the acute angulation of the coronary take-off, and compresses the vessel against the pulmonary trunk. ${ }^{27-30}$ Our histological findings suggest that the intramural course of the anomalous coronary artery in the aortic tunica media may be crucial because it produces a slit-like lumen. ${ }^{31}$ Thus in the absence of a fixed atherosclerotic coronary obstruction, the pathophysiological determinants of myocardial ischaemia are not readily reproducible, and this hinders the diagnosis of these congenital coronary anomalies that predispose to life-threatening arrhythmias.

None of our patients had had typical angina attacks and in half of them sudden death was the first manifestation of the coronary anomaly. Prodromal symptoms in the remaining subjects consisted of palpitation or syncopal episodes or both; electrocardiograms, when available, generally showed ventricular arrhythmias, such as isolated extrasystoles and unsustained ventricular tachycardia, in the absence of ST-T abnormalities. Therefore, in young patients with alarming symptoms of ventricular arrhythmia, an "ischaemic substrate" should be suspected even if exercise testing is normal and there is no chest pain. The origin and course of the coronary arteries should be investigated by a detailed echocardiographic study of the aortic root and, in selected cases, by coronary angiography. ${ }^{303233}$ 


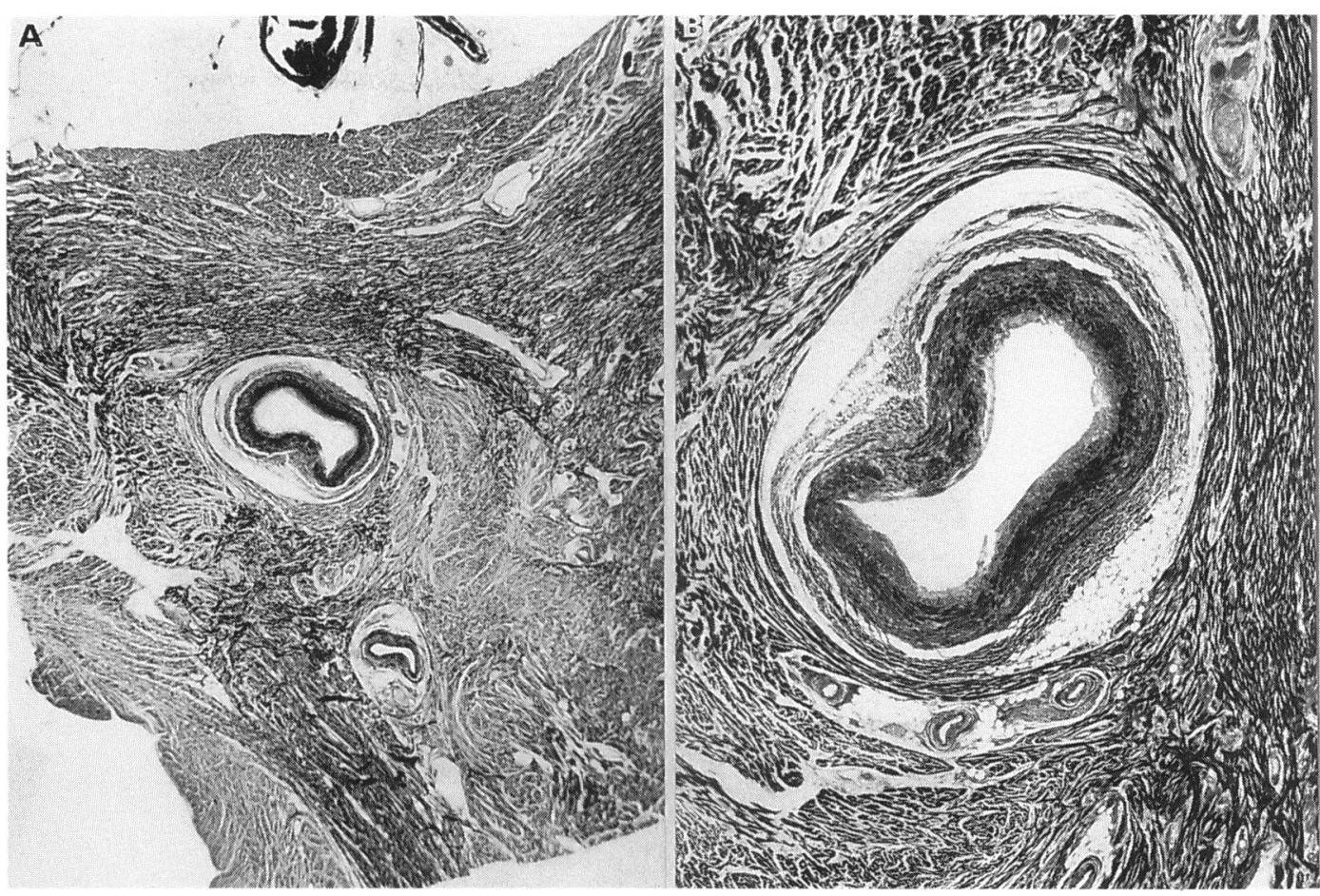

Figure 4 Histological examination of the heart of a 29 year old man who died suddenly at rest (case 9). (A) The anterior interventricular groove showing the intramyocardial course of the left anterior descending coronary artery. (Azan stain, original magnification, $\times 8)$. (B) Increased magnification of $(A)(\times 18)$ showing the myocardial sheath encircling the coronary segment and dysplasia of the myocardium producing disarray.
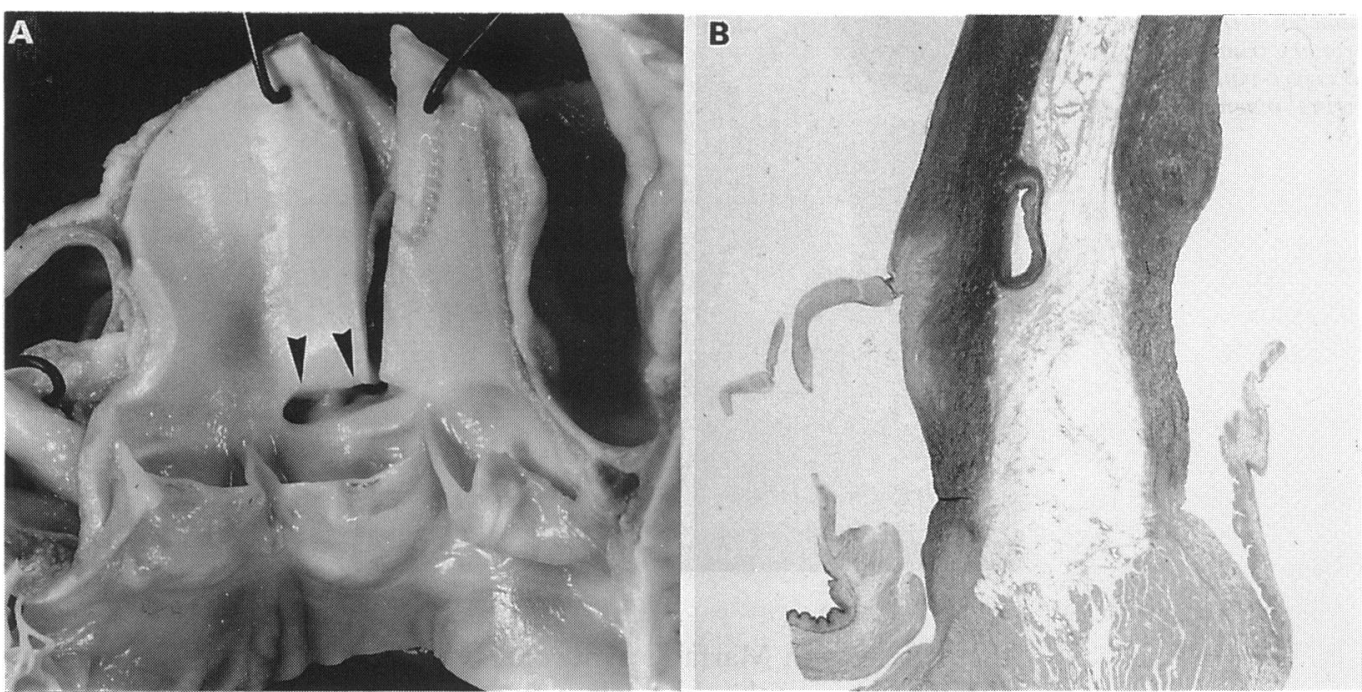

Figure 5 Cardiac morphology and histology in an 11 year old girl who died suddenly during effort (case 3). (A) Gross view of the aortic root showing that both coronary ostia arise from the right coronary sinus (arrows). ( $B$ ) Histological examination of the first segment of the left coronary artery showed that it ran in between the aorta and pulmonary artery. (Weigert-van Gieson, original magnification, $\times 6$ ).

Congenital malformations of the coronary ostium such as a valve-like ridge or slit shaped lumen, that cause ostial stenosis, have been found only at necropsy, usually in association with anomalous origin of the coronary artery from the wrong coronary sinus ${ }^{34}$ or in combination with severe atherosclerotic coronary artery disease. ${ }^{35}$ In our cases, however, the malformation was isolated and was also seen in children. Virmani et al postulated that ostial valve-like ridges may act as occlusion valves in the ostium, and thus predispose to sudden myocardial ischaemia. ${ }^{35}$ In our cases the fatal event occurred after eating (cases 10 and 11) or after effort (case 11), when a transient neurovagally mediated episode of hypotension could have been responsible for a sudden drop in aortic pressure, thus compromising the perfusion of the narrowed coronary ostium. Case 10 had had previous syncopal episodes that were interpreted as epileptic attacks.

The most common acquired nonatherosclerotic coronary artery disease in our series was spontaneous coronary artery dissection. This condition is usually an unrecognised cause of acute myocardial infarction or sudden death in young patients, especially peripartum women. ${ }^{36-40}$ Its aetiology is uncertain. Coronary artery dissection was idiopathic in two of our cases and related to pregnancy in 
Figure 6 Cardiac morphology and histology in a 7 year old girl who died suddenly after effort (case 7). (A) A valvelike ridge (arrow) obscured the right coronary ostium. (B) Histological examination showed that the ridge was an aortic wall plication. (Weigertvan Gieson, original magnification, $\times 8$ ).
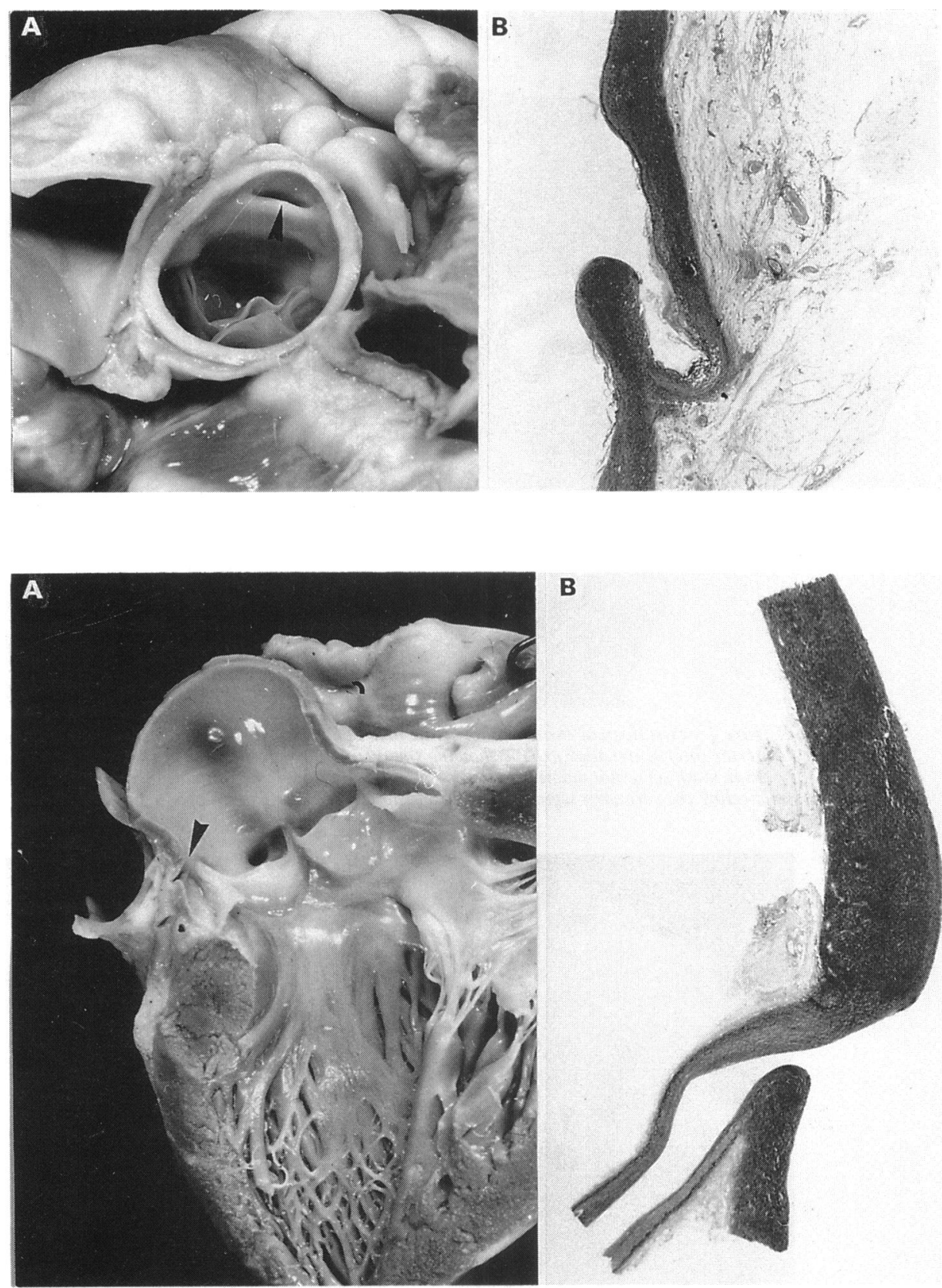

the patient with Marfan's syndrome who died suddenly during the third trimester.

This study suggests that non-atherosclerotic coronary artery disease is an important cause of fatal cardiac arrest in the young. It was present in one third of the cases of juvenile sudden coronary death that we studied. Congenital coronary diseases, consisting of apparent minor abnormalities of the ostium and of the origin and course of the coronary arteries, were the most frequent form of non-atherosclerotic coronary artery disease and were responsible for nearly $10 \%$ of juvenile sudden cardiac deaths in our series of necropsy cases. Angina or ischaemic electrocardiographic patterns were never seen, whereas half these cases had had arrhythmic symptoms (palpitation or syncope or both) and electrocardiographic signs (ventricular arrhythmias).

This study was supported by the Juvenile Sudden Death Research Project of the Veneto Region, Venice and by the
National Council for Research, Target Project FAT.MA., Rome, Italy.

\section{Addendum}

Since the submission of the paper, we have studied 23 additional cases of juvenile sudden death. We found evidence of nonatherosclerotic coronary artery disease in two of them. An 11 year old boy who died suddenly while playing soccer had an anomalous origin of the left coronary artery from the right aortic coronary sinus. A 14 year old girl who died suddenly at school had Takayasu arteritis that also affected the coronary ostia.

1 Kuller LH, Cooper M, Perper JA. Epidemiology of sudden death. Arch Intern Med 1972;129:714-9.

2 Cobb LA, Baum RS, Alvarez H, Shaffer WA. Resuscitation from out-of-hospital ventricular fibrillation: 4 years follow-up. Circulation 1975;51, 52 (suppl III):223-35.

3 Davies MJ, Thomas A. Thrombosis and acute coronary artery lesions in sudden cardiac ischemic death. $N$ Engl Med 1984;310:1137-40.

4 Driscoll DJ, Edwards WD. Sudden unexpected death in children and adolescents. J Am Coll Cardiol 1985;5 (suppl):118-21.

5 Waller BP. Exercise-related sudden death in young (age $\leqslant 30$ years) and old (age $\geqslant 30$ years) conditioned subjects. Cardiovasc Clin 1985;15:9-73. 
6 Topaz O, Edwards JE. Pathologic features of sudden death in children, adolescents, and voung adults. Chest 1985;148:303-8.

7 Maron BJ, Roberts WC, McAllister HA, Rosing DR, Epstein SE. Sudden death in young athletes. Circulation 1980;62:218-29.

8 Thiene G, Nava A, Corrado D, Rossi L, Pennelli N. Right ventricular cardiomyopathy and sudden death in young peiple. N Engl J Med 1988;318:129-33.

9 Corrado D, Thiene G, Nava A, Rossi L, Pennelli N. Sudden death in young competitive athletes: clinicopathologic correlations in 22 cases. Am J Med 1990;89:588-96.

10 Burke AP, Farb A, Virmani R, Goodin J, Smialek JE. Sports-related and non-sports-related sudden cardiac death in young adults. Am Heart $J$ 1991;121:568-75.

11 Thiene G, Pennelli N, Rossi L. Cardiac conduction system abnormalities as a possible cause of sudden death in young athletes. Hum Pathol 1983;14:704-9.

12 Liberthson RR, Nagel EL, Hirschman JC, Nussenfeld SR, Blackbourn BD, Davis JR. Pathophysiologic observations in prehospital ventricular fibrillation and sudden cardiac in prehospital ventricular fibrillation.

13 Friedman M, Manwaring JH, Roseman RH, Donlon G, Ortega $P$, Grube SM. Instantaneous and sudden deaths. Clinical and pathological differentation in coronary artery disease. JAMA 1973;225:1319-28.

14 Geiringer E. The mural coronary. Am Heart J 1951;41: 359-68.

15 Angelini P, Trivellato M, Donis J, Leachman RD. Myocardial bridges: a review. Prog Cardiovasc Dis 1983;26:75-88

16 Noble J, Bourassa MG, Patitlere R, et al. Myocardial bridging and milking effect of the left anterior descending coronary artery. Normal variant or obstruction. $A m J$ Cardiol 1976;37:993-9.

17 Ishimori $T$, Raizner AE, Chahine RA, Awdeh M, Luchi RJ. Myocardial bridges in man: clinical correlations and angiographic accentuation with nitroglycerin. Cath Cardiovasc Diagn 1977;3:59-65.

18 Faruqui AM, Maloy WC, Felner JM, Schlant RC, Logan WD, Symbas P. Symptomatic myocardial bridging of WD, Symbas P. Symptomatic myocardial brid

19 Feldman AM, Baughman KL. Myocardial infarction associated with a myocardial bridge. Am Heart $J$ 1986;111:784-7.

20 Vasan RS, Bahl VK, Rajani M. Myocardial infarction associated with a myocardial bridge. Int $J$ Cardiol 1989;25:240-1.

21 Morales AR, Romanelli R, Boucek RJ. The mural left anterior descending coronary artery, strenous exercise and sudden death. Circulation 1980;62:230-7. 22 Ciampricotti R, El Gamal M. Vasospastic coronary Cardiovasc Diagn 1988;14:118-20.

23 Binet JP, Guiraudon G, Langlois J, et al. Angine de poitrine et ponts musculaires sur l'artère interventriculaire antérieure: A propos de trois cas operes. Arch Mal Coeur 1978;71:251-8.

24 Froment R, Normand J, Amiel L. Angine de poitrine de type Prinzmetal. Coronaizes permeable mais spasm de l'interventriculaire antérieure en cours de crise. Arch Mal Coeur 1973;66:755-62.

25 Kuhn FE, Reagan K, Mohler ER III, Satler LF, Lu DY Rackley CE. Evidence for endothelial dysfunction and enhanced vasoconstriction in myocardial bridges. $A m$ Heart J 1991;122:1764-6.

26 Ferreira AG Jr, Trotter SE, Konig B Jr, Decourt LV, Fox K Olsen EGJ. Myocardial bridges: morphological and functional aspects. Br Heart $J$ 1991;66:364-7.

27 Cheitlin MD, DeCastro CM, McAllister HA. Sudden death as a complication of anomalous left coronary origin from the anterior sinus of Valsalva: a not-so-minor congenital anomaly. Circulation 1974;50:780-7.

28 Roberts WC, Siegel RJ, Zipes DP. Origin of the right coronary artery from the left sinus of Valsalva and its functional consequences: analysis of 10 necropsy patients. Am J Cardiol 1982;49:863-8.

29 Liberthson RR, Dinsmore RE, Fallon JT. Aberrant coronary artery origin from the aorta: report of 18 patients, review of the literature and delineation of natural history and management. Circulation 1974;59:748-54.

30 Liberthson RR, Southern JF. Sudden collapse of a 17-yearold girl during exertion. $N$ Engl J Med 1989;320:1475-83.

31 Nelson-Piercy C, Rickards AF, Yacoub MH. Aberran origin of the right coronary artery as a potential cause of origin of the right coronary artery as a potential cause of
sudden death: successful anatomical correction. Br Heart sudden death: succes

32 Weyman AE, Feigenbaum H, Dillon JC, Johnston KW, Eggleton RC. Non-invasive visualization of the left main coronary artery by cross-sectional echocardiography. Cir culation 1976;54:169-74

33 Maron BJ, Leon MB, Swain JA, Cannon III RO, Pellicia A Prospective identification by two-dimensional echocardiography of anamalous origin of the left main coronary artery from right sinus of Valsalva. $\mathrm{Am} J$ Cardiol 1991;68:140-2.

34 Roberts WC. Major anomalies of coronary arterial origin seen in adulthood. Am Heart $J$ 1986;11 1:941-63.

35 Virmani R, Chun PC, Goldstein RE, Robinowitz M, McAllister HA. Acute takeoffs of the coronary arteries along the aortic wall and congenital coronary ostial valvelike ridges: association with sudden death. $\mathrm{J} \mathrm{Am} \mathrm{Coll}$ Cardiol 1984;3:766-71.
C

36 Ciraulo D, Chesne R. Coronary arterial dissection: an unrecognized cause of myocardial infarction with subsequent coronary arterial patency. Chest 1978,73:677-9.

37 Baker P, Keyhani-Rofagha S, Graham R, Sharma H. Dissecting hematoma (aneurysm) of coronary arteries. $\mathrm{Am}$ $J$ Med 1986;80:317-9.

38 Shaver P, Carrig T, Baker W. Postpartum coronary artery dissection. Br Heart J 1978;40:83-6.

39 DeMaio SJ, Kinsella SH, Silverman ME. Clinical cours and long-term prognosis of spontaneous coronary artery dissection. Am J Cardiol 1989;64:471-4

40 Cocco P, Thiene G, Corrado D, Lodovichetti G, Pennelli N Ematoma (aneurisma) dissecante spontaneo delle coronarie e morte improvvisa. $G$ Ital Cardiol 1990;20:795-800. 